\title{
Comparision of Clinical and Laboratory Parameters in Culture Proven and Unproven Early Onset Sepsis in NICU Shrestha $S,{ }^{1}$ Dongol Singh $S,{ }^{1}$ Shrestha NC, ${ }^{1}$ Shrestha RPB, ${ }^{1}$ Madhup SK ${ }^{2}$
}

\author{
${ }^{1}$ Department of Pediatrics \\ ${ }^{2}$ Department of Microbiology \\ Dhulikhel Hospital - Kathmandu University Hospital \\ Kathmandu University School of Medical Sciences \\ Dhulikhel, Kavre, Nepal
}

\section{Corresponding Author}

Shrima Shrestha

Department of Pediatrics

Dhulikhel Hospital - Kathmandu University Hospital Kathmandu University School of Medical Sciences Dhulikhel, Kavre, Nepal

Email: sima_shrestha@yahoo.com

\section{Citation}

Shrestha S, Dongol Singh S, Shrestha NC, Shrestha RPB, Madhup SK. Comparision of Clinical and Laboratory Parameters in Culture Proven and Unproven Early Onset Sepsis in NICU. Kathmandu Univ Med J 2013;44(4):310-314.

\section{ABSTRACT}

\section{Backgroud}

Early onset sepsis remains a major cause for neonatal morbidity and mortality.

\section{Objectives}

The aim of this study was to describe and compare the clinical and laboratory characteristics of neonates in neonatal intensive care unit with culture positive and negative early onset sepsis and verify if there were any differences between the groups.

\section{Methods}

A one year comparative prospective study was conducted from January 2011 to January 2012 in neonatal intensive care unit (NICU), Dhulikhel Hospital, Kathmandu University Hospital (KUH).

\section{Results}

Out of 215 cases of suspected neonatal sepsis, 192 (89.30\%) cases of early onset sepsis were admitted in neonatal intensive care unit. Out of which 82 cases $(42.7 \%)$ had blood culture positive and 110 ( 57.3\%) had culture negative but compatible with features of clinical sepsis. There were no cases of culture proven meningitis and urinary tract infections.

The clinical characteristic did not show any statistical differences between the study groups except for seizure which was found to be high in culture positive cases $(p=0.041)$. The hospital stay in neonatal intensive care unit was significantly longer $(p=0.02)$ in culture positive cases. As for the laboratory test there were no differences found between the two study groups except cases of meningitis was more in culture proven early onset sepsis $(p=0.00)$. The overall mortality in early onset sepsis was $36.95 \%$. The higher mortality of $64.7 \%$ was seen in culture positive cases but statistically not significant.

\section{Conclusion}

Clinical manifestation and laboratory test were insufficient to distinguish between neonatal infection with blood culture positive and negative sepsis, hence both culture positive and negative cases should be treated promptly and equally.

\section{KEY WORD}

Culture proven early onset sepsis, neonates 


\section{INTRODUCTION}

Neonatal sepsis is a common cause of neonatal morbidity and mortality with an annual incidence of 2-6/1000 live births in the developed countries of the world. ${ }^{1}$ In the developing countries, the estimated incidence is 3-4 times higher and neonatal sepsis remains one of the most common reasons for admission in neonatal unit. ${ }^{2}$ This is mainly due to lack of health education, poor antenatal care and lack of trained staff to conduct deliveries. The association between maternal urinary tract infection, pyrexia, vaginal discharge and unclean vaginal examination during labour and development of early onset neonatal sepsis is well established. ${ }^{3}$

Currently, criteria for neonatal sepsis usually include documentation of infection in a newborn infant with a serious systemic illness in which non-infectious explanations for the abnormal pathophysiologic state are excluded or unlikely. However, even culture is not free from error because it can be falsely sterile, as suggested by postmortem cultures, or because of the low yield caused by insufficient sample volumes, intermittent or low-density bacteremia, or suppression of bacterial growth by earlier (i.e., intrapartum) antibiotic administration. ${ }^{4}$

Many studies try to correlate clinical and laboratory findings with the presence of proven sepsis. Until date, none of them has managed to define the most adequate parameters to diagnose neonatal sepsis with certainty. ${ }^{5}$ This study aims to describe and compare the clinical and laboratory characteristics of culture positive early onset sepsis (proven sepsis) and early onset sepsis with blood culture negative (clinical sepsis), and then assess whether differences exist between them.

\section{METHODS}

A descriptive study was carried out between January 2011 to January 2012 based on prospective data collected in neonatal intensive care unit (NICU), Dhulikhel Hospital, Kathmandu University Hospital (KUH). Approval for this research was obtained from the Institutional Review committee at Dhulikhel Hospital, KUH.

Newborns diagnosed with proven or unproven early onset sepsis hospitalized in NICU with any gestation age or weight was included in this study. All the cases of late onset sepsis, hyperbilirubinemia requiring only phototherapy and cases of congenital malformation without features of sepsis were excluded. Neonatal early-onset sepsis (EOS) is defined by the Centres for Disease Control and Prevention (CDC) as blood or cerebrospinal fluid culture proven infection occurring in the newborn that is younger than seven days of age. ${ }^{6}$

The diagnosis of EOS was based on at least two clinical (hyper- or hypothermia, apnea or bradycardia spells, increased oxygen requirement, feeding intolerance, abdominal distension, lethargy and hypotonia, hypotension, skin and subcutaneous lesions such as petechial rash, abscess, sclerema) and two laboratory criteria (white blood cell count $<5000$ or $>20,000 \times 10^{9}$ cells/L; immature/ total neutrophil $(\mathrm{I} / \mathrm{T})$ ratio $>0.2$; platelet count $<100,000$ $\times 10^{9} / \mathrm{L}$; C-reative protein (CRP) $>10 \mathrm{mg} / \mathrm{L}$ ). ${ }^{7}$ The blood specimen for culture were inoculated directly into Brain Heart Infusion broth. Proven sepsis was diagnosed, when in addition to the clinical and a laboratory sign of sepsis a true pathogen was isolated from a normally sterile body fluid, all other cases were termed clinical sepsis. ${ }^{8}$ Cerebral spinal fluid analysis was done in cases with positive CRP, all cases of positive blood culture and clinical features compatible with meningitis. Urine culture was done only in cases with congenital hydronephrosis and prolonged jaundice. Parametric tests were used for comparisons (t-test for variables with normal distribution), as well as nonparametric tests (when the variable are not in normal distribution), chi-square test and Fisher's exact test (when necessary) was done.

The collected data were analysed in Statistical Package for the Social Sciences (SPSS) software for Windows 17.0.

\section{RESULTS}

During this study period, 215 cases of suspected neonatal sepsis were admitted at NICU, Dhulikhel Hospital. There were $192(89.30 \%)$ cases of early onset sepsis. Out of which 82 cases $(42.7 \%)$ were blood culture proven but no cases of culture proven meningitis and urinary tract infections. 110( 57.3\%) were clinical sepsis.

The clinical characteristic were compared and there was no significant differences found between the two groups (Table 1). In table 2, birth weight, gestational age and duration of hospitalisation were compared where NICU stay was significantly longer in culure positive cases. The clinical alterations were compared between the two groups where Table 1. Comparison Between Clinical Characteristic of Infants Under Analysis.

\begin{tabular}{|c|c|c|c|c|c|}
\hline & & $\begin{array}{l}\text { Culture } \\
\text { positive }\end{array}$ & $\begin{array}{l}\text { Culture } \\
\text { negative }\end{array}$ & Total & $\begin{array}{l}p \\
\text { value }\end{array}$ \\
\hline \multirow[t]{2}{*}{ Gender } & Male & 46 & 69 & 115 & \multirow[t]{2}{*}{0.375} \\
\hline & Female & 36 & 41 & 77 & \\
\hline \multirow[t]{2}{*}{ Delivery type } & Vaginal & 54 & 79 & 133 & \multirow[t]{2}{*}{0.430} \\
\hline & C-section & 28 & 31 & 59 & \\
\hline \multirow[t]{2}{*}{ Birth weight } & $\leq 1500 \mathrm{gm}$ & 16 & 15 & 31 & \multirow[t]{2}{*}{0.323} \\
\hline & $>1500 \mathrm{gm}$ & 66 & 95 & 161 & \\
\hline \multirow[t]{2}{*}{ Gestation(weeks) } & $<37$ & 34 & 34 & 68 & \multirow[t]{2}{*}{0.170} \\
\hline & $>=37$ & 48 & 76 & 124 & \\
\hline \multirow[t]{2}{*}{ Place of delivery } & Inborn & 67 & 90 & 157 & \multirow[t]{2}{*}{1.00} \\
\hline & Outborn & 15 & 20 & 35 & \\
\hline \multirow{3}{*}{$\begin{array}{l}\text { Appropriateness } \\
\text { birth weight / } \\
\text { gestational age }\end{array}$} & SGA & 17 & 24 & 41 & \multirow[t]{3}{*}{0.886} \\
\hline & AGA & 60 & 81 & 141 & \\
\hline & LGA & 5 & 5 & 10 & \\
\hline
\end{tabular}


Table 2. Comparison Between Clinical Characteristic of Infant under Analysis, Continuous Variable.

\begin{tabular}{|c|c|c|c|c|c|}
\hline & Sepsis & Mean & S.D. & $\begin{array}{l}\max \text { max } \\
\text { max }\end{array}$ & $P$ value \\
\hline \multirow[t]{2}{*}{$\begin{array}{l}\text { Birth } \\
\text { weight(gm) }\end{array}$} & $\begin{array}{l}\text { Culture } \\
\text { positive }\end{array}$ & 2288 & 737.8 & $1000-3800$ & \multirow[t]{2}{*}{0.24} \\
\hline & $\begin{array}{l}\text { Culture } \\
\text { negative }\end{array}$ & 2412 & 712.5 & $800-4300$ & \\
\hline \multirow[t]{2}{*}{$\begin{array}{l}\text { Gestational } \\
\text { age (weeks) }\end{array}$} & $\begin{array}{l}\text { Culture } \\
\text { positive }\end{array}$ & 36.10 & 4.01 & $27-43$ & \multirow[t]{2}{*}{0.22} \\
\hline & $\begin{array}{l}\text { Culture } \\
\text { negative }\end{array}$ & 36.77 & 3.59 & $26-44$ & \\
\hline \multirow[t]{2}{*}{$\begin{array}{l}\text { NICU stay } \\
\text { (Days) }\end{array}$} & $\begin{array}{l}\text { Culture } \\
\text { positive }\end{array}$ & 9.33 & 13.07 & $1-110$ & \multirow[t]{2}{*}{0.02} \\
\hline & $\begin{array}{l}\text { Culture } \\
\text { negative }\end{array}$ & 5.21 & 3.94 & $1-19$ & \\
\hline
\end{tabular}

neurological features like seizure were significantly higher in culture positive cases. The clinical characteristic did not show any differences between the study groups(table 3). As for the laboratory test there were no differences found between the two study groups (Table 4).

In our study abnormal total leucocyte count was seen in $59.89 \%$, low in $0.52 \%$ and high in $58.53 \%$ of culture positive cases but statistically not significant.

Cerebeospinal fluid(CSF) analysis was done in 113 cases where it was suggestive of meningitis in 17 cases of blood culture positive cases and in 7 cases of culture negative

Table 3. Clinical Manifestation in Clinical and Proven Sepsis.

\begin{tabular}{|c|c|c|c|c|}
\hline & $\begin{array}{l}\text { Total } \\
(\mathrm{N}=192)\end{array}$ & $\begin{array}{l}\text { Culture } \\
\text { Positive } \\
(\mathrm{N}=82)\end{array}$ & $\begin{array}{l}\text { Culture } \\
\text { Negative } \\
(\mathrm{N}=110)\end{array}$ & $p$ value \\
\hline $\begin{array}{l}\text { Respiratory } \\
\text { distress }\end{array}$ & $100(52.08 \%)$ & 43 & 57 & 0.647 \\
\hline Poor cry & $21(10.93 \%)$ & 10 & 11 & 0.647 \\
\hline Poor sucking & $45(23.43 \%)$ & 18 & 27 & 0.732 \\
\hline Lethargy & $27(14.06 \%)$ & 15 & 12 & 0.207 \\
\hline Hypothermia & $31(16.14 \%)$ & 14 & 17 & 0.116 \\
\hline $\begin{array}{l}\text { Gastrointes- } \\
\text { tinal } \\
\text { manifesta- } \\
\text { tion }\end{array}$ & 19(9.9\%) & 9 & 10 & 0.808 \\
\hline Seizure & $36(18.75 \%)$ & 21 & 15 & 0.041 \\
\hline
\end{tabular}

Table 4. Laboratory Findings of Culture Positive and Negative Sepsis.

\begin{tabular}{|llcll|}
$\begin{array}{l}\text { Sepsis screen } \\
\text { parameter }\end{array}$ & $\begin{array}{l}\text { Total } \\
(\mathrm{N}=192)\end{array}$ & $\begin{array}{l}\text { Culture posi- } \\
\text { tive }(\mathrm{N}=82)\end{array}$ & $\begin{array}{l}\text { Culture } \\
\text { negative } \\
(\mathrm{N}=110)\end{array}$ & $\begin{array}{l}\mathbf{p} \\
\text { value }\end{array}$ \\
\hline Positive CRP & $29(15.1 \%)$ & $14(17.07 \%)$ & $15(13.63 \%)$ & 0.323 \\
\hline Leucopenia & $1(0.52 \%)$ & $1(1.21 \%)$ & $0(0 \%)$ & 0.427 \\
\hline Leucocytosis & $114(59.3 \%)$ & $48(58.53 \%)$ & $66(60 \%)$ & 0.882 \\
\hline I/T >= 0.2 & $30(15.62 \%)$ & $10(12.2 \%)$ & $20(18.2 \%)$ & 0.317 \\
\hline $\begin{array}{l}\text { Thrombocyto- } \\
\text { penia }\end{array}$ & $32(16.66 \%)$ & $15(18.3 \%)$ & $17(15.45 \%)$ & 0.696 \\
\hline $\begin{array}{l}\text { CSF analysis } \\
\text { Meningitis }\end{array}$ & $24(21.23 \%)$ & $17(70.83 \%)$ & $7(29.16 \%)$ & 0.00 \\
\hline
\end{tabular}

cases. However, none of them grew organism in CSF analysis. There was significant association of meningitis and culture positive cases with $\mathrm{p}$ value of 0.000 .

The culture positive (68.8\%) and culture negative (31.2\%) cases were discharged. The overall mortality in early onset sepsis is $36.95 \%$. The higher mortality of $64.7 \%$ was seen in culture positive cases but statistically not significant.

\section{DISCUSSION}

In our study culture positive rate in early onset sepsis is $42.7 \%$ which is comparable to $51.38 \%$ in study done in Rural India but higher than the study in Iran where it was $9.5 \%{ }^{10,11}$ The varying results may be due to different study population and difference in definition of proven sepsis. Negative blood culture results do not imply the inexistence of bacterial sepsis in neonatal infection, as the sensitivity of blood culture is low, which justifies the difficulty to isolate the germ even when present in the bloodstream. ${ }^{12}$ The male to female ratio of suspected sepsis $1.5: 1$ is comparable with other studies. ${ }^{13,14}$ The male preponderence in neonatal septicemia may be linked to the X-linked immunoregulatory gene factor contributing to the host's susceptibility to infections in male. ${ }^{15}$

The clinical manifestation did not show any difference between the study groups. Similar findings were observed in Iran. ${ }^{11}$ However, study in Rural India showed EOS is significantly higher in preterm and very low birthweight. ${ }^{10}$ Similarly, study conducted by Vishownathan et al showed no statistical difference in demographic characteristic like birth weight, mode of delivery and place of delivery. However, prematurity and male child were significantly high in blood culture positive cases. ${ }^{16}$ The fact that incidence of neonatal sepsis is more in male neonate and preterm babies could have explained the significant culture positive rate. ${ }^{15}$

The clinical characteristics noticed at the start of the onset of sepsis did not show any statistical difference between the two groups in our study.

Clinical alterations are described as predictive signs with low diagnostic value for sepsis, needing other associated diagnostic proof to confirm the condition. ${ }^{17}$ Even if the clinical alterations associated with neonatal sepsis are not specific, but can be attributed to another problems or diseases than neonatal sepsis. Authors report that, besides laboratory alterations, the patient's clinical situation should be valued, as the risk of bacterial infections in asymptomatic infants is very low. ${ }^{18}$ The duration of NICU stay was significantly higher in culture positive patient in our study. Respiratory distress is one of the most consistent symptoms seen in early onset sepsis. ${ }^{9}$ In our study also respiratory distress accounts for $52.08 \%$ which is the most common symptom. The presence of clinical alteration in clinical and proven early onset sepsis was statistically not significant except for neurological feature which was high 
in culture positive cases.

Study in Tanzania compared the clinical characteristic among culure positive and negative early onset and late onset sepsis where inability to feed, lethargy, convulsion and cyanosis was found to be significantly associated with early onset sepsis. ${ }^{19}$

In our study abnormal total leucocyte count was seen in $59.89 \%$, low in $0.52 \%$ and high in $58.53 \%$ of culture positive cases but statistically not significant. Similary study by Bhat showed abnormal total leucocyte in $36.4 \%$ neonates where it was low in $5.7 \%$ and high in $30.7 \%$ of early onset sepsis. ${ }^{20}$

Study conducted by May et al and Stoll et al showed in bacteremic infants, the incidence of meningitis may be as high as $23 \%$. $^{21,22}$ Blood culture alone cannot be used to decide who needs a lumbar puncture, because blood cultures can be negative in up to $38 \%$ of infants with meningitis. ${ }^{23,24}$ In our study cerebrospinal fluid analysis revealed meningitis in $29.26 \%$ but none of the cerebrospinal fluid grew organism. Similarly, study by Borna found only one positive CSF culture. ${ }^{11}$ Similar study conducted by Jayior didnot find any positive CSF culture among 263 infants $<72$ hours of age and recommended that lumbar puncture be reserved for selected infants. ${ }^{25}$

\section{REFERENCES}

1. Jana AK, Sridhar.S. Clinical diagnosis of sepsis. Journal of Neonatology 2009; 23(1):44-47.

2. Rodríguez Cervilla J, Fraga JM, García Riestra C, Fernández Lorenzo JR, Martínez Soto I. Neonatal sepsis: epidemiologic indicators and relation to birth weight and length of hospitalization time. An Esp Pediatr. 1998; 48(4):401-8.

3. Anwer SK, Mustafa S, Pariyani S, Ashraf S, Taufiq KM.Neonatal sepsis: an etiological study. J Pak Med Assoc. 2000; 50(3):91-4.

4. Bhutta ZA, Yusuf K. Early-onset neonatal sepsis in Pakistan: a case control study of risk factors in a birth cohort. Am J Perinatol. 1997; 14(9):577-81.

5. Squire E, Favara B, Todd J. Diagnosis of neonatal bacterial infection: hematologic and pathologic findings in fatal and nonfatal cases. Pediatrics. 1979; 64(1):60-4.

6. JPolin RA. The "ins and outs" of neonatal sepsis. Pediatr. 2003; 143(1):3-4

7. Phares CR, Lynfield R, Farley MM, Mohle-Boetani J, Harrison LH et.al. Epidemiology of invasive group $B$ streptococcal disease in the United States, 1999-2005. JAMA. 2008; 299(17):2056-65.

8. Auriti C, Ravà L, Di Ciommo V, Ronchetti MP, Orzalesi M. Short antibiotic prophylaxis for bacterial infections in a neonatal intensive care unit: a randomized controlled trial. J Hosp Infect. 2005 ; 59(4):292-8.

9. O'grady NP, Alexander M, Dellinger EP, Gerberding JL, Heard SO, Maki DG et.al. Guidelines for the prevention of intravascular catheterrelated infections. Am J Infect Control. 2002; 30(8):476-89.

10. K. Swarnkar, M. Swarnkar . A Study of Early Onset Neonatal Sepsis with Special Reference to Sepsis Screening Parameters in A Tertiary Care Centre Of Rural India. The Internet Journal of Infectious Diseases 2012; 10(1). DOI: 10.5580/2be5.

11. H. Borna, S. Borna. Value of Laboratory Tests and C - reactive protein In the Detection of Neonatal Sepsis. The Internet Journal of Pediatrics and Neonatology. 2005; 5(2). DOI: 10.5580/1a94.
Study in India showed positive CRP, leucopenia, neutropenia, IT $\geq 0.2$, thrombocytopenia is not significant between the culture positive and negative group which was similar to our finding. ${ }^{10}$

In our study the overall mortality of EOS was $36.95 \%$. The mortality in culture positive cases $(64.7 \%)$ were higher than negative cases (35.3\%) but statistically not significant.

Study by Swarnkar reported mortality rate in early onset sepsis of $19.4 \%$ and that of culture positive early onset sepsis cases was $16.2 \% .^{10}$ The mortality rate varies depending on the definition of the early onset sepsis and the comparision becomes difficult. In a study carried out in Kenya in which early-onset sepsis is considered at $\leq 3$ days of life, there was mortality of $4 \%$ in early-onset and $10 \%$ in late-onset sepsis. In India, where early onset sepsis is considered up to $\leq 6$ days of life, the authors found a mortality of $49 \%$ in early onset sepsis and $86 \%$ in lateonset sepsis. ${ }^{26,27}$

\section{CONCLUSION}

Clinical manifestation and laboratory test were insufficient to distinguish between neonatal infection with blood culture positive and negative sepsis, hence both culture positive and negative cases should be treated promptly.

12. Gerdes JS. Clinicopathologic approach to the diagnosis of neonatal sepsis. Clin Perinatol. 1991; 18(2):361-81.

13. Khinchi YR, Kumar A, Yadhav S. Profile of Neonatal sepsis. Journal of college of Medical Sciences-Nepal. 2010; 6(2):1-6.

14. Sriram R. Correlation of blood culture results with the sepsis score and the sepsis screen in the diagnosis of neonatal septicaemia. International Journal of Biological and Medical Research. 2011; 2(1): $360-368$

15. Sharma M, Goel N, Chaudhary U, Aggarwal R, Arora DR. Bacteraemia in children. Indian J Pediatr. 2002; 69(12):1029-32.

16. Viswanathan R, Singh AK, Ghosh C, Dasgupta S, Mukherjee S, Basu S Profile of neonatal septicaemia at a district-level sick newborn care unit. J Health Popul Nutr. 2012; 30(1):41-8.

17. Weber MW, Carlin JB, Gatchalian S, Lehmann D, Muhe L, Mulholland EK. WHO Young Infants Study Group. Predictors of neonatal sepsis in developing countries. Pediatr Infect Dis J. 2003; 22(8):711-7.

18. Escobar GJ, Li DK, Armstrong MA, Gardner MN, Folck BF, Verdi JE et.al. Neonatal sepsis workups in infants $>/=2000$ grams at birth: $A$ population-based study. Pediatrics. 2000; 106(2 Pt 1):256-63.

19. Kayange N, Kamugisha E, Mwizamholya DL, Jeremiah S, Mshana SE. Predictors of positive blood culture and deaths among neonates with suspected neonatal sepsis in a tertiary hospital, Mwanza-Tanzania. BMC Pediatr. 2010; 4:10-39.

20. Bhat Y R, Lincy P. Early Onset of Neonatal Sepsis: Analysis of the Risk Factors and the Bacterial Isolates by Using the BacT Alert System. Journal of Clinical and Diagnostic Research. 2011; (Suppl-2),5(7): 1385-88.

21. May M, Daley AJ, Donath S, Isaacs D. Australasian Study Group for Neonatal Infections. Early onset neonatal meningitis in Australia and New Zealand, 1992-2002. Arch Dis Child Fetal Neonatal Ed. 2005; 90(4):F324-7. 
22. Stoll BJ, Hansen N, Fanaroff AA, Wright LL, Carlo WA, Ehrenkranz RA et.al. To tap or not to tap: high likelihood of meningitis without sepsis among very low birth weight infants. Pediatrics. 2004; 113(5):1181-6.

23. Garges HP, Moody MA, Cotten CM, Smith PB, Tiffany KF, Lenfestey $R$ et.al. Neonatal meningitis: what is the correlation among cerebrospinal fluid cultures, blood cultures, and cerebrospinal fluid parameters? Pediatrics. 2006; 117(4):1094-100.

24. Shah SS, Ebberson J, Kestenbaum LA, Hodinka RL, Zorc JJ. Age-specific reference values for cerebrospinal fluid protein concentration in neonates and young infants. J Hosp Med. 2011; 6(1):22-7.
25. A Jayior. Mokuolu OA. "Evaluation of neonatal with risk for infection /suspected sepsis: is routine lumbar puncture necessary in the first 72hours of life?"Trop Med Int Health. 1997 Mar;2(3):284-8.

26. Musoke RN, Revathi G. Emergence of multidrug-resistant gramnegative organisms in a neonatal unit and the therapeutic implications. J Trop Pediatr. 2000; 46(2):86-91.

27. Tallur SS, Kasturi AV, Nadgir SD, Krishna BV. Clinico-bacteriological study of neonatal septicemia in Hubli. Indian J Pediatr. 2000; 67(3):169-74. 